\title{
The Relation of Physical Activity, Sedentary Behaviors, and Academic Achievement Is Mediated by Fitness and Bedtime
}

\author{
Heidi J. Syväoja, Anna Kankaanpää, Jouni Kallio, Harto Hakonen, Janne Kulmala, Charles H. Hillman, \\ Anu-Katriina Pesonen, and Tuija H. Tammelin
}

\begin{abstract}
Background: This study investigated the associations of subjectively and objectively measured physical activity (PA) and sedentary behavior with academic achievement. We further examined whether aerobic fitness, obesity, and bedtime mediate these associations. Methods: This study included 970 children aged 9-15 years (52.3\% girls) from 9 schools throughout Finland. Register-based academic achievement [grade point average (GPA)] as well as self-reported and accelerometer-measured PA/ sedentary behavior were assessed during spring 2013. Aerobic fitness (assessed via a maximal shuttle run test), body composition (assessed via bioimpedance analysis), and self-reported bedtime were collected. Structural equation modeling was applied to examine the associations. Standardized regression coefficients are presented. Results: Self-reported PA had a direct positive $[\beta=$ $0.084 ; 95 \%$ confidence interval (CI), 0.023 to 0.145$]$ and an indirect positive association with GPA through higher aerobic fitness $(\beta=0.061 ; 95 \%$ CI, 0.033 to -0.087$)$. Accelerometer-based PA was not associated with GPA. Self-reported screen time had an indirect negative association with GPA through later bedtime $(\beta=-0.071 ; 95 \% \mathrm{CI},-0.096$ to -0.035$)$ and lower aerobic fitness ( $\beta=-0.039 ; 95 \% \mathrm{CI},-0.059$ to 0.019$)$. Nonscreen sedentary time had a direct positive $(\beta=0.193 ; 95 \% \mathrm{CI}, 0.101$ to -0.289$)$ and an indirect negative association with GPA through lower aerobic fitness $(\beta=-0.040 ; 95 \%$ CI, -0.063 to -0.016$)$. Conclusions: Participating in PA, avoiding excessive screen time, and going to bed earlier may benefit academic achievement.
\end{abstract}

Keywords: academic performance, moderate to vigorous physical activity, screen time, sedentary time, adolescents

Globally, children spend extensive amounts of time being sedentary, ${ }^{1}$ and only one-third of children are physically active enough to gain health benefits. ${ }^{2}$ Accompanying these trends, the rates of childhood overweight and obesity, along with poor fitness, are escalating. ${ }^{3,4}$ These trends have raised concerns about the effects of a physically inactive lifestyle on children's health during maturation and across the lifespan, as physical activity (PA) continues to decrease and sedentary time (ST) continues to increase from childhood to adolescence and adulthood. ${ }^{5,6}$ The association of a physically active lifestyle with learning outcomes has also recently received considerable attention. Previous studies have suggested that excessive screen time $e^{7,8}$ and excess adiposity ${ }^{9,10}$ may predict poorer academic achievement (AA), whereas regular PA and higher aerobic fitness ${ }^{11,12}$ benefit AA.

Sufficient sleep has also been related to better AA. ${ }^{13,14}$ The periods of sleep, together with time spent in PA and sedentary behavior (SB), have been suggested to constitute a composite whole, as the time spent in one of these behaviors necessarily displaces time spent in another. ${ }^{15}$ Although these behaviors are closely related to each other, the associations with AA have thus far been studied only in isolation or with a partial adjustment for time spent in other activities. To date, there are no comprehensive studies examining associations of PA, SB, sleep, fitness, and obesity with AA in the same model, further accounting for possible indirect associations.

Syväoja, Kankaanpää, Kallio, Hakonen, Kulmala, and Tammelin are with the LIKES Research Centre for Physical Activity and Health, Jyväskylä, Finland. Hillman is with the Depts of Psychology and Health Sciences, Northeastern University, Boston, MA. Pesonen is with the Institute of Behavioural Sciences, University of Helsinki, Helsinki, Finland. Tammelin (tuija.tammelin@likes.fi) is corresponding author.
The purpose of the present study was to determine the associations of subjectively and objectively measured PA and SB, including both screen-based and nonscreen-based ST, with AA. We further examined whether PA or SB has indirect associations with AA through aerobic fitness, obesity, or bedtime. We hypothesized that higher levels of PA and lower levels of SB are associated with better AA and that these associations are mediated by aerobic fitness, obesity, and bedtime.

\section{Methods}

\section{Study Population}

This study was conducted in the spring of 2013 as part of a larger study of the national "Finnish Schools on the Move" program. The participants were recruited from 9 primary and lower secondary schools, with a wide geographical representation of Finland. Of the 1710 students from grades 4-7 who were invited to participate in the study, only 970 students aged 9-15 years (52.3\% girls) agreed to participate. Those students who participated in this study were more often girls (52\% vs $40 \%$ ), and they ran more laps in 20-m shuttle run test indicating higher aerobic fitness (47 vs 42 laps) compared with their nonparticipating classmates. Both the students and their guardians gave written informed consent to participate. The study protocol was approved by the ethics committee of the University of Jyväskylä.

\section{Academic Achievement}

The education services provided students' grades in the following school subjects: native language (in most cases, Finnish or Swedish); first foreign language (begun in grade 3); mathematics; physics; chemistry; biology; geography; history; religion or ethics; 
visual arts; music; and physical education. The grades refer to numerical assessment on a scale of 4-10, where 4 denotes a failure and 10 denotes excellent knowledge and skills. Grade point averages (GPAs) were calculated as a mean of the individual grades to indicate overall AA in the analysis.

\section{Self-Reported PA, SB, and Bedtime}

Children completed a web-based questionnaire. They evaluated their moderate to vigorous PA (MVPA) by describing how many days they were physically active for a total of at least 60 minutes per day during a typical week. The response categories were as follows: 0 day, 1 day, 2 days,..., 7 days. A short description of MVPA and examples assisted in answering the question. ${ }^{16}$ Children evaluated their screen time by reporting how many hours a day they usually (1) watch television (including videos, YouTube or similar websites, and DVDs $)^{17}$; (2) play computer or video games (not including exergames) ${ }^{17}$; and (3) use time for keeping in touch with others via social media (eg, e-mail, chat, Twitter, Facebook) in their free time on weekdays and weekends separately. The response options were as follows: not at all, about half an hour per day, about an hour per day, about 2 hours per day ... about 5 hours per day or more. Total daily screen time variable is a weighted mean of 3 screen time questions (1)-(3) during weekdays and weekend days. Children reported their typical bedtime on nights when they have to go to school the next morning. The response options were as follows: no later than 21:00, 21:30, 22:00, ..., 02:00, or later. Test-retest agreement for self-reported MVPA has been good (intraclass correlation $=.74$ ); for screen time questions, moderate to substantial (intraclass correlation $=.54-.74$ ); and for bedtime, good (intraclass correlation $=.75) .{ }^{16}$

\section{Accelerometer-Based PA and ST}

PA and ST were assessed with GT3X+ and wGT3X+ accelerometers (ActiGraph, Pensacola, FL). Participants were instructed to wear a monitor on the right hip during waking hours for 7 full consecutive days, except while bathing or doing other water-based activities. Data were collected in raw $30-\mathrm{Hz}$ acceleration standardly filtered and converted into 15-second epoch counts. A customized Visual Basic macro for Excel software was used for data reduction. Readings including $\geq 500$ minutes per day on 3 days or more of measured time between 07:00 and 23:00 were required for a valid monitoring period. ${ }^{18}$ Nonwear time was defined as periods of 30 minutes of consecutive zero counts. ${ }^{19}$ Over 20,000 counts per minute data were ruled out as spurious accelerations. ${ }^{20}$ Evenson et al's ${ }^{21}$ cut points were used to calculate MVPA ( $\geq 2296$ counts per minute) and ST ( $\leq 100$ counts per minute). Accelerometerbased ST was expressed as a percentage of daily registration time.

\section{Aerobic Fitness, Body Fat Percentage, and Stage of Puberty}

Aerobic fitness was measured with a maximal 20-m shuttle run test following the Eurofit protocol ${ }^{22}$ with slight modifications to number of laps per stage. The number of 20-m trials that the children were able to keep up with an accelerating pace was used to indicate the level of aerobic fitness in the analyses. Body composition, especially body fat percentage, was measured via a body composition analyzer InBody 720 (InBody, Seoul, South Korea). Children's stage of puberty was determined via the self-assessment questionnaire and categorized according to the Tanner puberty stage. ${ }^{23}$

\section{Confounding Factors}

A parent or guardian of each child completed a web-based questionnaire and assessed the child's potential learning difficulties by answering the following question: "Does your child have any diagnosed learning difficulties?" (categorization: $1=$ yes and $0=$ no or do not know). The parent or guardian reported the level of mother's education (categorization: $1=$ tertiary level education and $0=$ basic or upper secondary education).

\section{Statistical Analyses}

The descriptive statistics were calculated using SPSS 20.0 for Windows (SPSS Inc, Chicago, IL), and all further analyses were conducted using Mplus statistical package (version 7). ${ }^{24}$ The descriptive statistics are presented as means and standard deviations or percentages (\%). Differences in the study variables between girls and boys were tested via Student's $t$ test or Pearson's chi-square test. The sample correlation coefficients were estimated and tested for significance.

The reciprocal associations among the variables were studied via structural equation modeling. All the regressions were adjusted for potential confounding variables. First, the associations of PA and SB variables with GPA were studied. To extract nonscreen ST from accelerometer-measured ST, a Cholesky factoring of the predictors was applied. ${ }^{25}$ Cholesky factoring allows a residual from a regression model to be an explanatory variable for further modeling. Two latent variables were created: self-reported screen time and nonscreen ST representing the accelerometer-measured $\mathrm{ST}$, from which the variation explained by the self-reported screen time is excluded. GPA was regressed simultaneously on the PA, screen time, and nonscreen ST.

Second, the proposed mediator variables, including aerobic fitness, body fat percentage, and bedtime, were entered into the model. The indirect associations of interest were calculated and tested for significance. As the data were clustered within classes, the standard errors of the parameter estimates of the models were calculated using the special feature of Mplus (TYPE = COMPLEX).

Missing data were assumed to be missing at random. The correlations and the parameters of the models were estimated using the full information maximum likelihood method with robust standard errors. Full information maximum likelihood produces unbiased parameter estimates under missing at random. The Satorra-Bentler scaled chi-square test, the comparative fit index, the Tucker-Lewis index, the root mean square error of approximation, and the standardized root mean square residual were used to evaluate the goodness of fit of the models. The model fits the data well if the $P$-value for the chi-square test is nonsignificant, comparative fit index and Tucker-Lewis index values are close to .95 , the root mean square error of approximation value is below .06 , and the standardized root mean square residual value is below $.08 .^{26}$ If the model did not fit the data adequately well, modification indices were examined.

\section{Results}

Sex-specific distributions and sex differences in observed variables are presented in Table 1.

Self-reported MVPA was positively associated with GPA $[r=.113 ; 95 \%$ confidence interval (CI), .042 to .184], whereas accelerometer-based MVPA was not $(r=.021 ; 95 \% \mathrm{CI},-.062$ 
Table 1 Sex-Specific Distributions and Sex Differences in Observed Variables

\begin{tabular}{|c|c|c|c|c|c|c|c|}
\hline & \multicolumn{2}{|c|}{ Total $(n=970)$} & \multicolumn{2}{|c|}{ Boys $(n=462)$} & \multicolumn{2}{|c|}{ Girls $(n=508)$} & \multirow[b]{2}{*}{$P^{a}$} \\
\hline & $\mathbf{n}$ & Mean (SD) & $\mathbf{n}$ & Mean (SD) & $\mathbf{n}$ & Mean (SD) & \\
\hline Age, $y$ & 969 & $12.5(1.3)$ & 462 & $12.6(1.3)$ & 507 & $12.5(1.3)$ & .59 \\
\hline Academic achievement (GPA, scale $4-10)^{\text {b }}$ & 853 & $8.2(0.7)$ & 407 & $8.0(0.7)$ & 446 & $8.4(0.7)$ & $<.001$ \\
\hline Aerobic fitness ${ }^{c}$ & 883 & $41.6(18.9)$ & 415 & $47.1(20.4)$ & 468 & $36.8(16.0)$ & $<.001$ \\
\hline Body fat percentage, $\%$ & 914 & $18.4(8.4)$ & 429 & $15.3(8.2)$ & 485 & $21.2(7.5)$ & $<.001$ \\
\hline Bedtime $^{\mathrm{d}}$ & 947 & $3.0(1.4)$ & 451 & $3.0(1.4)$ & 496 & $3.0(1.4)$ & .75 \\
\hline Self-reported MVPA (d/wk with $\geq 60$-min MVPA) ${ }^{e}$ & 949 & $5.4(1.9)$ & 452 & $5.7(1.9)$ & 497 & $5.1(1.8)$ & $<.001$ \\
\hline Accelerometer-based MVPA, $\mathrm{min} / \mathrm{d}^{\mathrm{f}}$ & 766 & $52.7(21.7)$ & 341 & $59.3(23.7)$ & 425 & $47.5(18.4)$ & $<.001$ \\
\hline Sedentary time, $\% / \mathrm{d}^{\mathrm{g}}$ & 766 & $64.8(7.4)$ & 341 & $63.0(7.6)$ & 425 & $66.3(6.9)$ & $<.001$ \\
\hline Screen time, $\mathrm{h} / \mathrm{d}$ & 948 & $4.2(2.8)$ & 451 & $4.5(3.1)$ & 497 & $4.0(2.5)$ & .002 \\
\hline Stage of puberty ${ }^{\mathrm{h}}$ & 913 & $2.7(1.0)$ & 430 & $2.7(1.0)$ & 483 & $2.6(0.9)$ & .24 \\
\hline Learning difficulties (yes) & 627 & $11.5 \%$ & 305 & $13.1 \%$ & 322 & $9.9 \%$ & .21 \\
\hline Mother's education (tertiary level education) & 618 & $70.9 \%$ & 301 & $74.4 \%$ & 317 & $67.5 \%$ & .06 \\
\hline Number of schools & 9 & & & & & & \\
\hline Number of classes & 84 & & & & & & \\
\hline
\end{tabular}

Abbreviations: GPA, grade point average; MVPA, moderate to vigorous physical activity.

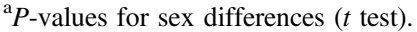

${ }^{\mathrm{b}} \mathrm{GPA}$ (a scale of 4-10, where 4 denotes a failure and 10 denotes excellent knowledge and skills) was calculated as means of the following individual grades: native language (in most cases, Finnish or Swedish); first foreign language (started in grade 3); mathematics; physics; chemistry; biology; geography; history; religion or ethics visual arts; music; and physical education.

${ }^{\mathrm{c}}$ Aerobic fitness was measured with a maximal 20-m shuttle run test. The number of 20-m trials that the children were able to keep up with the excitable signal was used to indicate the level of aerobic fitness.

${ }^{\mathrm{d}}$ Children self-reported their usual bedtimes. The response options were as follows: $1=$ no later than 21:00, $2=21: 30,3=22: 00,4=22: 30,5=23: 00,6=23: 30,7=24: 00$, $8=00: 30,9=01: 00,10=01: 30,11=02: 00$, or later.

${ }^{e}$ Children self-reported how many days they were physically active for a total of at least 60 minutes per day during a typical or usual week. The response categories were as follows: $1=0$ day, $2=1$ day, $3=2$ days, $\ldots, 8=7$ days.

${ }^{\mathrm{f}}$ MVPA was measured with the ActiGraph accelerometer using a cutoff value 2296 counts per minute.

${ }^{g}$ Sedentary time was measured by the ActiGraph accelerometer using a cutoff value 100 counts per minute and expressed as percentage of daily monitoring time (\%/d).

${ }^{\mathrm{h}}$ State of puberty was measured using the self-assessment questionnaire and categorized accordingly to Tanner puberty stage.

to .103). Self-reported screen time was negatively associated with GPA ( $r=-.294 ; 95 \% \mathrm{CI},-.354$ to .234$)$, whereas accelerometerbased ST was not ( $r=.048 ; 95 \% \mathrm{CI},-.032$ to .128$)$.

Self-reported MVPA was positively $(\beta=0.141 ; 95 \% \mathrm{CI}, 0.078$ to -0.204$)$, screen time was negatively $(\beta=-0.173 ; 95 \% \mathrm{CI}$, -0.243 to -0.104$)$, and nonscreen ST $(\beta=0.153 ; 95 \%$ CI, 0.052 to -0.253 ) was positively associated with GPA after controlling for sex, age, mother's education, and learning difficulties.

The hypothesized path model included indirect paths from self-reported MVPA to GPA through aerobic fitness and body fat percentage; indirect paths from screen time to GPA through aerobic fitness, body fat percentage, and bedtime; and indirect paths from nonscreen ST to GPA through aerobic fitness and body fat percentage. Additionally, direct paths from self-reported MVPA, screen time, and nonscreen ST to GPA were estimated. The model fitted the data well, and the estimation results are presented in Figure 1A and Tables 2 and 3. Self-reported MVPA had a direct positive $(\beta=0.084)$ and an indirect positive association with GPA through higher aerobic fitness $(\beta=0.060)$. Screen time had an indirect negative association with GPA through later bedtime $(\beta=$ $-0.066)$ and lower aerobic fitness $(\beta=-0.039)$. Nonscreen ST had a direct positive $(\beta=0.195)$ and an indirect negative association with GPA through lower aerobic fitness $(\beta=-0.040)$. Body fat percentage did not mediate the associations of PA or SB with AA. The model explained $36.1 \%$ of the variance in GPA.

Furthermore, the model was separately fitted for girls (Figure 1B, Table 3, and Online Supplementary Table 1) and boys (Figure 1C, Table 3, and Online Supplementary Table 2).
Among girls, the model fitted the data well, after the association between self-reported MVPA and bedtime was additionally estimated (modification indices $=9.08$ for the association). Among boys, the model fitted the data well. The associations were relatively similar in all models with few exceptions. Self-reported MVPA had a direct positive association with GPA $(\beta=0.123)$ and an indirect negative association with GPA through later bedtime only among girls $(\beta=-0.015)$. Screen time and body fat percentage had a direct negative associations with GPA only among girls $(\beta=-0.135$ and $\beta=-0.140$, respectively). The model for girls explained $39.5 \%$ and for boys $28.8 \%$ of the variance in GPA.

\section{Discussion}

\section{Main Findings}

Our data demonstrated that self-reported PA was positively and screen time negatively associated with AA in children. These associations were mediated by aerobic fitness and bedtime but not by body fat percentage. Furthermore, accelerometer-based nonscreen ST had not only a direct positive association but also an indirect negative association with AA through lower aerobic fitness. Accelerometer-based MVPA was unrelated to AA.

\section{PA and AA}

The present results indicate that higher levels of self-reported PA and better aerobic fitness are associated with higher levels of AA, 
A All

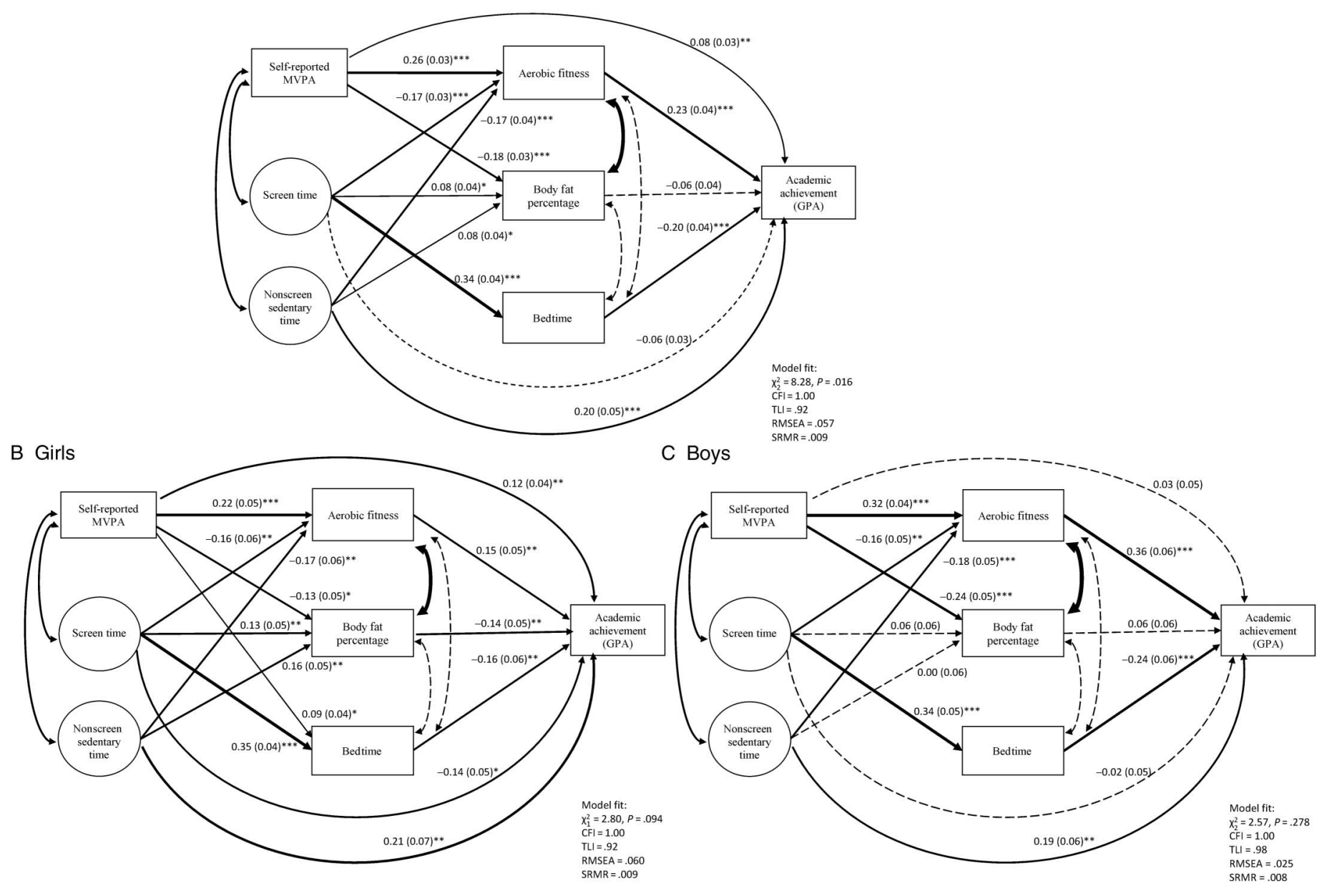

Figure 1 - Path diagrams of the models among (A) all children $(n=970),(B)$ girls $(n=508)$, and $(C)$ boys $(n=468)$. Circles denote latent variables created using a Cholesky factoring of the predictors and squares denote observed variables. Standardized regression coefficients (standard errors) are presented. The thicknesses of the lines are proportional to the size of coefficients. CFI indicates comparative fit index; GPA, grade point average; MVPA, moderate to vigorous physical activity; RMSEA, root mean square error of approximation; SRMR, standardized root mean square residual; TLI, TuckerLewis index. $* P<.05$. $* * P<.01 . * * * P<.001$.

supporting previous findings. ${ }^{8,10,11,27}$ Specifically, in this study, higher aerobic fitness mediated the positive association of selfreported PA and AA among all children. Interestingly, among girls, the direct association between self-reported PA and AA remained after the mediator aerobic fitness was added to the model but disappeared among boys. These results provide partial support for the cardiovascular fitness hypothesis, which suggests that aerobic fitness is a physiological mediator that explains the various mental health benefits of PA. ${ }^{28,29}$ However, there are also studies that have not demonstrated the mediating effect of aerobic fitness. ${ }^{10,30}$ The results of the present study suggest that, among girls, PA may have a positive association with AA independent of aerobic fitness, whereas among boys, the association is dependent on aerobic fitness.

The positive association of PA and aerobic fitness with AA may be due to several possible mechanisms. PA and aerobic fitness have been suggested to enhance cognitive functions by inducing functional and structural changes in subcortical structures such as the hippocampus and the basal ganglia, ${ }^{31}$ through cortical structures such as prefrontal cortex, ${ }^{32}$ by increasing levels of brainderived neurotrophic factor and by enhancing cerebrovascular function. ${ }^{33}$ Beside the beneficial effects on cognition, PA may improve academic engagement, ${ }^{34}$ self-esteem, ${ }^{31,35}$ and school contentment, ${ }^{36}$ all of which predict better AA. Furthermore, motor function may be an important driver in the effects of PA on the cognitive prerequisites of learning. ${ }^{10}$

Accelerometer-based MVPA was not associated with AA, supporting previous studies. ${ }^{8,37}$ However, other studies have shown both positive $\mathrm{e}^{12,30}$ and negative ${ }^{38}$ relationships between accelerometer-based MVPA and AA. Observed inconsistencies between accelerometer-based and self-reported PA may be due to the limitations of both methods: children may have difficulties estimating the level of PA and may overestimate their PA compared with objective measures, ${ }^{39}$ while accelerometers are not capable of assessing all physical activities such as swimming, cycling, and activities that require lifting any kind of load. ${ }^{40}$ Different measurements may also represent different constructs and contexts of $\mathrm{PA}$ in association with $\mathrm{AA}^{8}$ : self-reported PA may assess PA in a wider sense, taking, for example, a skill-specific PA requiring balance and agility as well as social aspects of PA, which typically do not accumulate activity counts. Alternatively, accelerometer-based MVPA may illustrate cardiovascular activity with increased heart rate and respiratory frequency over other forms of PA. Accordingly, capturing children's PA in a wider sense (ie, subjective PA) may have stronger association with AA. 
Table 2 The Estimated Parameters of the Path Model

\begin{tabular}{|c|c|c|c|c|}
\hline All $(n=970)$ & $\boldsymbol{\beta}$ & SE & $95 \% \mathrm{Cl}$ & $P$ \\
\hline \multicolumn{5}{|l|}{ Grade point average } \\
\hline Self-reported MVPA & 0.084 & 0.031 & 0.023 to 0.145 & .007 \\
\hline Screen time & -0.064 & 0.034 & -0.130 to 0.003 & .06 \\
\hline Nonscreen sedentary time & 0.195 & 0.048 & 0.101 to 0.289 & $<.001$ \\
\hline Aerobic fitness & 0.230 & 0.043 & 0.145 to 0.315 & $<.001$ \\
\hline Body fat percentage & -0.057 & 0.041 & -0.136 to 0.023 & .17 \\
\hline Bedtime & -0.195 & 0.040 & -0.274 to -0.116 & $<.001$ \\
\hline Sex (girl) & 0.291 & 0.031 & 0.230 to 0.352 & $<.001$ \\
\hline Age & -0.142 & 0.050 & -0.241 to -0.044 & .005 \\
\hline Mother's high education & 0.159 & 0.038 & 0.085 to 0.233 & $<.001$ \\
\hline Learning difficulties & -0.240 & 0.039 & -0.317 to -0.164 & $<.001$ \\
\hline \multicolumn{5}{|l|}{ Aerobic fitness } \\
\hline Self-reported MVPA & 0.259 & 0.032 & 0.196 to 0.323 & $<.001$ \\
\hline Screen time & -0.170 & 0.033 & -0.234 to -0.106 & $<.001$ \\
\hline Nonscreen sedentary time & -0.173 & 0.035 & -0.242 to -0.105 & $<.001$ \\
\hline Sex (girl) & -0.205 & 0.032 & -0.272 to -0.139 & $<.001$ \\
\hline Age & 0.340 & 0.044 & 0.254 to 0.426 & $<.001$ \\
\hline Mother's high education & 0.113 & 0.038 & 0.016 to 0.187 & .003 \\
\hline Learning difficulties & -0.127 & 0.038 & -0.201 to -0.053 & $<.001$ \\
\hline Body fat percentage & $-0.486^{\mathrm{a}}$ & 0.029 & -0.544 to -0.429 & $<.001$ \\
\hline Bedtime & $0.045^{\mathrm{a}}$ & 0.035 & -0.022 to 0.113 & .19 \\
\hline \multicolumn{5}{|l|}{ Body fat percentage } \\
\hline Self-reported MVPA & -0.183 & 0.034 & -0.249 to -0.117 & $<.001$ \\
\hline Screen time & 0.078 & 0.036 & 0.006 to 0.149 & .03 \\
\hline Nonscreen sedentary time & 0.080 & 0.040 & 0.002 to 0.158 & .04 \\
\hline Sex (girl) & 0.316 & 0.032 & 0.254 to 0.379 & $<.001$ \\
\hline Age & -0.009 & 0.034 & -0.076 to 0.057 & .78 \\
\hline Mother's high education & -0.069 & 0.041 & -0.150 to 0.011 & .09 \\
\hline Learning difficulties & 0.086 & 0.035 & 0.016 to 0.155 & .02 \\
\hline Bedtime & $-0.006^{\mathrm{a}}$ & 0.035 & -0.074 to 0.062 & .87 \\
\hline \multicolumn{5}{|l|}{ Bedtime } \\
\hline Screen time & 0.336 & 0.036 & 0.266 to 0.406 & $<.001$ \\
\hline Sex (girl) & 0.023 & 0.031 & -0.037 to 0.084 & .45 \\
\hline Age & 0.340 & 0.038 & 0.265 to 0.415 & $<.001$ \\
\hline Mother's high education & 0.005 & 0.032 & -0.058 to 0.067 & .89 \\
\hline Learning difficulties & -0.068 & 0.042 & -0.150 to 0.014 & .10 \\
\hline \multicolumn{5}{|l|}{ Self-reported MVPA } \\
\hline Screen time & $-0.139^{\mathrm{a}}$ & 0.042 & -0.220 to -0.057 & .001 \\
\hline Nonscreen sedentary time & $-0.179^{\mathrm{a}}$ & 0.046 & -0.269 to -0.088 & $<.001$ \\
\hline
\end{tabular}

Note. Standardized regression coefficients and correlation coefficients are presented.

Abbreviations: $\beta$, standardized regression coefficient; CI, confidence interval; MVPA, moderate to vigorous physical activity.

${ }^{\mathrm{a}}$ Correlation coefficient.

Interestingly, in this study, self-reported PA also had a negative indirect association with AA through later bedtime among girls. This finding may be explained by differential academic cultures between boys and girls, wherein girls tend to put more effort into their schoolwork, have higher expectations of themselves, ${ }^{41}$ and be more vulnerable to internal distress than boys. ${ }^{42}$ Performance-oriented girls may feel pressure to succeed in both academics and sports; hence, they spend most of their time doing schoolwork, but still remain physically active and engage in other activities typical for adolescents at the expense of their bedtime. Furthermore, the results may highlight the importance of the timing of exercise. Late evening exercise may induce later bedtimes and attenuate recovery. ${ }^{43}$ Research demonstrates that suboptimal sleep and bedtimes impair learning capacity, AA, and neurocognitive functioning. ${ }^{13,14}$

\section{SB and AA}

In line with previous studies, ${ }^{7,8}$ our results showed that recreational screen time is negatively associated with learning outcomes. The 
Table 3 Standardized Estimates of Indirect Associations of Self-Reported Moderate to Vigorous Physical Activity, Screen Time, and Nonscreen Sedentary Time With Academic Achievement Through Aerobic Fitness, Body fat Percentage, and Bedtime

\begin{tabular}{|c|c|c|c|c|}
\hline Specific indirect effect & Estimate $^{a}$ & SE & $95 \% \mathrm{Cl}$ & $P$ \\
\hline \multicolumn{5}{|l|}{ All $(\mathrm{n}=970)$} \\
\hline \multicolumn{5}{|l|}{ Self-reported MVPA } \\
\hline Aerobic fitness $\rightarrow$ GPA & 0.060 & 0.014 & 0.033 to 0.087 & $<.001$ \\
\hline Body fat percentage $\rightarrow$ GPA & 0.010 & 0.008 & -0.004 to 0.025 & .17 \\
\hline \multicolumn{5}{|l|}{ Screen time } \\
\hline Aerobic fitness $\rightarrow$ GPA & -0.039 & 0.010 & -0.059 to -0.019 & $<.001$ \\
\hline Body fat percentage $\rightarrow$ GPA & -0.004 & 0.004 & -0.012 to 0.003 & .24 \\
\hline Bedtime $\rightarrow$ GPA & -0.066 & 0.016 & -0.096 to -0.035 & $<.001$ \\
\hline \multicolumn{5}{|l|}{ Nonscreen sedentary time } \\
\hline Aerobic fitness $\rightarrow$ GPA & -0.040 & 0.012 & -0.063 to -0.016 & .001 \\
\hline Body fat percentage $\rightarrow$ GPA & -0.005 & 0.004 & -0.013 to 0.004 & .27 \\
\hline \multicolumn{5}{|l|}{ Girls $(n=508)$} \\
\hline \multicolumn{5}{|l|}{ Self-reported MVPA } \\
\hline Aerobic fitness $\rightarrow$ GPA & 0.032 & 0.013 & 0.007 to 0.057 & .01 \\
\hline Body fat percentage $\rightarrow$ GPA & 0.018 & 0.011 & -0.002 to 0.039 & .09 \\
\hline Bedtime $\rightarrow$ GPA & -0.015 & 0.007 & -0.028 to -0.001 & .04 \\
\hline \multicolumn{5}{|l|}{ Screen time } \\
\hline Aerobic fitness $\rightarrow$ GPA & -0.023 & 0.012 & -0.047 to 0.000 & .05 \\
\hline Body fat percentage $\rightarrow$ GPA & -0.018 & 0.010 & -0.038 to 0.002 & .07 \\
\hline Bedtime $\rightarrow$ GPA & -0.056 & 0.012 & -0.099 to -0.014 & .01 \\
\hline \multicolumn{5}{|l|}{ Nonscreen sedentary time } \\
\hline Aerobic fitness $\rightarrow$ GPA & -0.026 & 0.013 & -0.052 to 0.001 & .06 \\
\hline Body fat percentage $\rightarrow$ GPA & -0.022 & 0.012 & -0.045 to 0.001 & .06 \\
\hline \multicolumn{5}{|l|}{ Boys $(n=462)$} \\
\hline \multicolumn{5}{|l|}{ Self-reported MVPA } \\
\hline Aerobic fitness $\rightarrow$ GPA & 0.115 & 0.024 & 0.068 to 0.161 & $<.001$ \\
\hline Body fat percentage $\rightarrow$ GPA & -0.014 & 0.014 & -0.041 to 0.013 & .31 \\
\hline \multicolumn{5}{|l|}{ Screen time } \\
\hline Aerobic fitness $\rightarrow$ GPA & -0.060 & 0.020 & -0.099 to -0.020 & .003 \\
\hline Body fat percentage $\rightarrow$ GPA & 0.003 & 0.005 & -0.007 to 0.014 & .54 \\
\hline Bedtime $\rightarrow$ GPA & -0.078 & 0.025 & -0.127 to -0.030 & .002 \\
\hline \multicolumn{5}{|l|}{ Nonscreen sedentary time } \\
\hline Aerobic fitness $\rightarrow$ GPA & -0.066 & 0.023 & -0.111 to -0.021 & .004 \\
\hline Body fat percentage $\rightarrow$ GPA & 0.000 & 0.004 & -0.007 to 0.007 & .98 \\
\hline
\end{tabular}

Abbreviations: CI, confidence interval; GPA, grade point average; MVPA, moderate to vigorous physical activity.

${ }^{a}$ Standardized estimate of indirect association.

association was indirect through later bedtime and lower aerobic fitness. Only among girls, did the direct association remain after the mediating factors were added to the model. Some studies have also reported inconsistent results. ${ }^{44,45}$ These inconsistencies may be explained by the content and context of screen time: Not all screen time has a similar role in benefitting or impairing children's learning outcomes. ${ }^{46}$

Our results support the time displacement theory. ${ }^{47}$ Even though screen time may not be harmful to AA in itself, excessive amounts of screen time may displace other activities important to cognition and AA such as sleep, homework, or reading. Screen time may also displace time for PA and weaken aerobic fitness, thereby affecting cognition. Screen time offers children intense and sensational experiences, which increases their desire for this kind of SB, and it is incompatible with other behaviors. ${ }^{47}$ Additionally, excessive screen time may increase attention difficulties, ${ }^{48}$ and school problem behavior such as lower homework completion and negative attitudes toward school, ${ }^{47,48}$ all of which may predict academic failure.

In this study, accelerometer-based nonscreen ST had not only a direct positive association but also an indirect negative association, with AA through lower aerobic fitness. Previous studies have not found an association between accelerometer-based ST and AA., However, in these studies, total ST was used as an independent variable. In this study, applying Cholesky factoring of the predictors enabled us to differentiate the associations of screen time and nonscreen ST with AA. These results suggest that ST also includes activities that may be beneficial to AA, supporting results 
obtained from self-report data. ${ }^{7}$ Some SB may be beneficial to attention and executive functions, ${ }^{49}$ which, in turn, are important for AA. ${ }^{11}$ However, these results also suggest that higher levels of $\mathrm{SB}$ may result in lower aerobic fitness, resulting in worse AA.

\section{Obesity and AA}

Obesity has also been suggested to compromise learning outcomes. ${ }^{9,10,50}$ In this study, only among girls, body fat percentage had a direct negative association with AA, supporting the results of Esteban-Cornejo et al, ${ }^{9}$ who found that the association of body fat and AA may be stronger among girls than boys. The authors speculated that obesity may affect girls' self-esteem more strongly than boys', explaining the adverse association between body fat and AA. As physical inactivity may lead to obesity, body fat content may mediate the effects of PA and SB on AA. However, in this study, body fat percentage did not mediate the association of PA, screen time, or nonscreen ST with AA. The present findings partially support those of Davis et al, ${ }^{51}$ who reported that PA and obesity may have independent associations with cognition, as shown via measures of AA.

\section{Study Strengths and Limitations}

To our knowledge, this is the first study demonstrating the associations of PA, SB, bedtime, fitness, and obesity with AA using a single comprehensive model. Further, instead of hypothesizing that, for example, aerobic fitness underlies both PA and AA, aerobic fitness was assumed to lie on a pathway between PA and AA. If a potential mediating variable was misspecified as a confounding factor, the association of PA or SB with AA would likely disappear, which may cause misleading conclusions. This is also the first study differentiating the associations of screen time and accelerometer-based nonscreen ST with AA. Moreover, we used a large and representative study sample, PA and SB were assessed in various ways, aerobic fitness and body fat were measured, and we used structural equation modeling. This cross-sectional study design limits drawing any conclusions regarding causality. In the future, longitudinal and intervention studies are needed to confirm these results. We did not assess the content of screen time or nonscreen ST, which limits the interpretation of the results. Furthermore, we did not measure sleep duration or quality, only bedtime.

\section{Conclusions}

In summary, children who had higher levels of self-reported PA had better aerobic fitness and AA. Additionally, children who had higher levels of self-reported screen time, had later bedtimes, lower aerobic fitness, and poorer AA. However, the accelerometer-based nonscreen ST seemed to include behaviors that may be beneficial to AA. These results highlight the importance of behavioral guidance for physically active lifestyles, not only from a public health perspective but also from a learning perspective, in the modernday sedentary world.

\section{Acknowledgments}

This study was supported by a grant (no. 273971) from the Academy of Finland and by a grant (OKM/92/626/2013) from the Finnish Ministry of Education and Culture.

\section{References}

1. Pate RR, Mitchell JA, Byun W, Dowda M. Sedentary behaviour in youth. Br J Sports Med. 2011;45(11):906-913. PubMed doi:10.1136/ bjsports-2011-090192

2. Ekelund U, Tomkinson G, Armstrong N. What proportion of youth are physically active? Measurement issues, levels and recent time trends. Br J Sports Med. 2011;45(11):859-865. PubMed doi:10. 1136/bjsports-2011-090190

3. Lakshman R, Elks CE, Ong KK. Childhood obesity. Circulation. 2012;126(14):1770-1779. PubMed doi:10.1161/ CIRCULATIONAHA.111.047738

4. Tomkinson GR, Olds TS. Secular changes in pediatric aerobic fitness test performance: the global picture. Med Sport Sci. 2007;50:46-66. PubMed doi:10.1159/000101075

5. Biddle SJH, Pearson N, Ross GM, Braithwaite R. Tracking of sedentary behaviours of young people: a systematic review. Prev Med. 2010;51(5):345-351. PubMed doi:10.1016/j.ypmed.2010.07. 018

6. Nader PR, Bradley RH, Houts RM, Mcritchie SL, Brien MO. Moderate-to-vigorous physical activity from ages 9 to 15 years. $J$ Am Med Assoc. 2008;300(3):295-305. PubMed doi:10.1001/jama. 300.3.295

7. Esteban-Cornejo I, Martinez-Gomez D, Sallis JF, et al. Objectively measured and self-reported leisure-time sedentary behavior and academic performance in youth: the UP\&DOWN Study. Prev Med. 2015;77:106-111. PubMed doi:10.1016/j.ypmed.2015.05.013

8. Syväoja HJ, Kantomaa MT, Ahonen T, Hakonen H, Kankaanpää A, Tammelin TH. Physical activity, sedentary behavior, and academic performance in Finnish children. Med Sci Sports Exerc. 2013;45(11):2098-2104. PubMed doi:10.1249/MSS. 0b013e318296d7b8

9. Esteban-Cornejo I, Tejero-González CM, Castro-Piñero J, et al. Independent and combined influence of neonatal and current body composition on academic performance in youth: the UP \& DOWN Study. Pediatr Obes. 2015;10(3):157-164. PubMed doi:10.1111/ijpo. 239

10. Kantomaa MT, Stamatakis E, Kankaanpää A, et al. Physical activity and obesity mediate the association between childhood motor function and adolescents' academic achievement. Proc Natl Acad Sci U S A. 2013;110(5):1917-1922. PubMed doi:10.1073/pnas.1214574110

11. Donnelly JE, Hillman CH, Castelli D, et al. Physical activity, fitness, cognitive function, and academic achievement in children. $\mathrm{Med} \mathrm{Sci}$ Sports Exerc. 2016;48(6):1197-222. PubMed doi:10.1249/MSS. 0000000000000901

12. Booth JN, Leary SD, Joinson C, et al. Associations between objectively measured physical activity and academic attainment in adolescents from a UK cohort. Br J Sports Med. 2014;48(3):265-270. PubMed doi:10.1136/bjsports-2013-092334

13. Dewald JF, Meijer AM, Oort FJ, Kerkhof GA, Bögels SM. The influence of sleep quality, sleep duration and sleepiness on school performance in children and adolescents: a meta-analytic review. Sleep Med Rev. 2010;14(3):179-189. PubMed doi:10.1016/j.smrv. 2009.10.004

14. Curcio G, Ferrara M, De Gennaro L. Sleep loss, learning capacity and academic performance. Sleep Med Rev. 2006;10(5):323-337. PubMed doi:10.1016/j.smrv.2005.11.001

15. Chastin SFM, Palarea-Albaladejo J, Dontje ML, Skelton DA. Combined effects of time spent in physical activity, sedentary behaviors and sleep on obesity and cardio-metabolic health markers: a novel compositional data analysis approach. PLOS ONE. 2015;10(10): e0139984. PubMed doi:10.1371/journal.pone.0139984 
16. Liu Y, Wang M, Tynjälä J, et al. Test-retest reliability of selected items of Health Behaviour in School-aged Children (HBSC) survey questionnaire in Beijing, China. BMC Med Res Methodol. 2010;10:73. PubMed doi:10.1186/1471-2288-10-73

17. Inchley J, Currie D, Young T, et al. Growing Up Unequal: Gender and Socioeconomic Differences in Young People's Health and WellBeing: Health Behaviour in School-aged Children (HBSC) Study: International Report from the 2013/2014 Survey. Health Policy for Children and Adolescents. No. 7. Denmark: WHO Regional Office for Europe; 2016.

18. Cooper AR, Goodman A, Page AS, et al. Objectively measured physical activity and sedentary time in youth: the International children's accelerometry database (ICAD). Int J Behav Nutr Phys Act. 2015;12(1):113. PubMed doi:10.1186/s12966-015-0274-5

19. Domazet SL, Tarp J, Huang T, et al. Associations of physical activity, sports participation and active commuting on mathematic performance and inhibitory control in adolescents. PLOS ONE. 2016;11(1): e0146319. PubMed doi:10.1371/journal.pone.0146319

20. Heil DP, Brage S, Rothney MP. Modeling physical activity outcomes from wearable monitors. Med Sci Sports Exerc. 2012;44(1)(suppl 1): S50-S60. PubMed doi:10.1249/MSS.0b013e3182399dcc

21. Evenson KR, Catellier DJ, Gill K, Ondrak KS, McMurray RG. Calibration of two objective measures of physical activity for children. J Sports Sci. 2008;26(14):1557-1565. PubMed doi:10.1080/ 02640410802334196

22. Tomkinson G, Léger L, Olds T, Cazorla G. Secular trends in the performance of children and adolescents (1980-2000): an analysis of 55 studies of the $20 \mathrm{~m}$ shuttle run test in 11 countries. Sports Med. 2003;33(4):285-300. PubMed

23. Taylor SJ, Whincup PH, Hindmarsh PC, Lampe F, Odoki K, Cook DG. Performance of a new pubertal self-assessment questionnaire: a preliminary study. Paediatr Perinat Epidemiol. 2001;15(1):88-94. PubMed doi:10.1046/j.1365-3016.2001.00317.x

24. Muthén L, Muthén B, eds. Mplus User's Guide. 7th ed. Los Angeles, CA: Muthén \& Muthén; 2012.

25. de Jong PF. Hierarchical regression analysis in structural equation modeling. Struct Equ Modeling. 1999;6(2):198-211. doi:10.1080/ 10705519909540128

26. Hu L, Bentler PM. Cutoff criteria for fit indexes in covariance structure analysis: conventional criteria versus new alternatives. Struct Equ Modeling. 1999;6(1):1-55. doi:10.1080/10705519909540118

27. Wittberg RA, Northrup KL, Cottrell LA. Children's aerobic fitness and academic achievement: a longitudinal examination of students during their fifth and seventh grade years. Am J Public Health. 2012;102(12):2303-2307. PubMed doi:10.2105/AJPH.2011. 300515

28. Åberg MAI, Pedersen NL, Torén K, et al. Cardiovascular fitness is associated with cognition in young adulthood. Proc Natl Acad Sci U S A. 2009;106(49):20906-20911. PubMed doi:10.1073/pnas. 0905307106

29. North TC, McCullagh P, Tran ZV. Effect of exercise on depression. Exerc Sport Sci Rev. 1990;18(1):379-415. PubMed

30. Kwak L, Kremers SPJ, Bergman P, Ruiz JR, Rizzo NS, Sjöström M. Associations between physical activity, fitness, and academic achievement. J Pediatr. 2009;155(6):914-918.e1. PubMed doi:10. 1016/j.jpeds.2009.06.019

31. Lubans D, Richards J, Hillman C, et al. Physical activity for cognitive and mental health in youth: a systematic review of mechanisms. Pediatrics. 2016;138(3):e20161642. doi:10.1542/peds.2016-1642

32. Chaddock-Heyman L, Erickson KI, Voss MW, et al. The effects of physical activity on functional MRI activation associated with cognitive control in children: a randomized controlled intervention. Front Hum Neurosci. 2013;7:72. PubMed doi:10.3389/fnhum.2013. 00072

33. Davenport MH, Hogan DB, Eskes GA, Longman RS, Poulin MJ. Cerebrovascular reserve: the link between fitness and cognitive function? Exerc Sport Sci Rev. 2012;40:153-158. PubMed

34. Mullender-Wijnsma MJ, Hartman E, de Greeff JW, Doolaard S, Bosker RJ, Visscher C. Physically active math and language lessons improve academic achievement: a cluster randomized controlled trial. Pediatrics. 2016;137(3):e20152743. PubMed doi:10.1542/peds. 2015-2743

35. Kristjánsson AL, Sigfúsdóttir ID, Allegrante JP. Health behavior and academic achievement among adolescents: the relative contribution of dietary habits, physical activity, body mass index, and selfesteem. Health Educ Behav. 2010;37(1):51-64. doi:10.1177/ 1090198107313481

36. Kristjánsson A, Sigfúsdóttir I, Allegrante J, Helgason A. Adolescent health behavior, contentment in school, and academic achievement. Am J Health Behav. 2009;33(1):69-79. PubMed

37. LeBlanc MM, Martin CK, Han H, et al. Adiposity and physical activity are not related to academic achievement in school-aged children. J Dev Behav Pediatr. 2012;33(6):486-494. doi:10.1097/ DBP.0b013e31825b849e

38. Esteban-Cornejo I, Tejero-González CM, Martinez-Gomez D, et al. Objectively measured physical activity has a negative but weak association with academic performance in children and adolescents. Acta Paediatr. 2014;103(11):e501-e506. PubMed doi:10.1111/apa. 12757

39. Corder K, van Sluijs EMF, McMinn AM, Ekelund U, Cassidy A, Griffin SJ. Perception versus reality awareness of physical activity levels of British children. Am J Prev Med. 2010;38(1):1-8. PubMed doi:10.1016/j.amepre.2009.08.025

40. Strath SJ, Kaminsky LA, Ainsworth BE, et al. Guide to the assessment of physical activity: clinical and research applications: a scientific statement from the American Heart Association. Circulation. 2013;128(20):2259-2279. PubMed doi:10.1161/01.cir.0000435708. 67487.da

41. Warrington M, Younger M, Williams J. Student attitudes, image and the gender gap. Br Educ Res J. 2000;26(3):393-407. doi:10.1080/ 01411920050030914

42. Pomerantz EM, Altermatt ER, Saxon JL. Making the grade but feeling distressed: gender differences in academic performance and internal distress. J Educ Psychol. 2002;94(2):396-404. doi:10.1037/ 0022-0663.94.2.396

43. Myllymäki T, Kyröläinen H, Savolainen K, et al. Effects of vigorous late-night exercise on sleep quality and cardiac autonomic activity. $J$ Sleep Res. 2011;20(1 pt 2):146-153. doi:10.1111/j.1365-2869.2010. 00874.x

44. Haapala EA, Poikkeus A-M, Kukkonen-Harjula K, et al. Associations of physical activity and sedentary behavior with academic skills-a follow-up study among primary school children. PLOS ONE. 2014;9(9):e107031. PubMed doi:10.1371/journal.pone.0107031

45. Borzekowski DLG, Robinson TN. The remote, the mouse, and the no. 2 pencil: the household media environment and academic achievement among third grade students. Arch Pediatr Adolesc Med. 2005;159(7):607-613.

46. Kirkorian H, Wartella E, Anderson DR. Media and young children's learning. Future Child. 2008;18(1):39-61. doi:10.1353/foc.0.0002

47. Sharif I, Wills TA, Sargent JD. Effect of visual media use on school performance: a prospective study. J Adolesc Health. 2010;46(1):5261. doi:10.1016/j.jadohealth.2009.05.012 
48. Johnson JG, Cohen P, Kasen S, Brook JS. Extensive television viewing and the development of attention and learning difficulties during adolescence. Arch Pediatr Adolesc Med. 2007;161(5):480486. PubMed

49. Syväoja H, Tammelin T, Ahonen T, Kankaanpää A, Kantomaa M. The associations of objectively measured physical activity and sedentary time with cognitive functions in school-aged children. PLoS ONE. 2014;9(7):e103559. doi:10.1371/journal.pone.0103559
50. Kamijo K, Khan NA, Pontifex MB, et al. The relation of adiposity to cognitive control and scholastic achievement in preadolescent children. Obesity. 2012;20(12):2406-2411. doi:10.1038/oby.2012.112

51. Davis CL, Tkacz JP, Tomporowski PD, Bustamante EE. Independent associations of organized physical activity and weight status with children's cognitive functioning: a matched-pairs design. Pediatr Exerc Sci. 2015;27(4):477-487. PubMed doi:10.1123/pes.20150044 